\title{
REDUCING LEAD EXPOSURE IN CHILDREN IN BROKEN HILL
}

Hugh Burke and Bill Balding

Population Health Unit

Far West Area Health Service

David Lyle

Department of Rural Health

University of Sydney, Broken Hill

Broken Hill is a mining town located in the semi-arid region of western NSW. It is the site of one of the world's richest deposits of silver, lead and zinc. ${ }^{1}$ Mining activities began here in 1883 and continue to the present time. In the early days, lead poisoning was a cause for concern but was primarily viewed as an occupational hazard. ${ }^{2}$ The evidence emerging in the 1980s describing the health effects of lead, particularly in pre-school aged children, and the downward revision by the National Health and Medical Research Council (NHMRC) of the blood lead level of concern, ${ }^{3}$ motivated a re-evaluation of lead exposure as a public health issue in the town.

Early in 1992, the NSW Government made funds available to investigate the lead problem in Broken Hill. This investigation demonstrated the multiple sources of the lead, and its widespread distribution in and around the city. However, cleaning the whole town and preventing the further release of lead into the environment was not feasible as a primary strategy. ${ }^{4}$ The situation required an approach that targeted specific sources of lead that could be linked to children with a high blood lead level. The aim was both to reduce the amount of lead at the probable source and to modify its rate of release or spatial distribution.

This approach was supported by a range of educational, behavioural and environmental interventions for all children but was specifically reinforced for those children aged less than five years with high blood lead levels. These interventions were designed to prevent the likelihood of lead already available in the environment being taken up. The need for medical intervention using chelation therapy was rare. In the early years of the Program, only a few children with extremely high blood lead levels received this treatment.

In 1994 the management strategy was formally launched. The Lead Management Program aims to reduce blood lead levels in Broken Hill children to that observed in noncontaminated areas elsewhere in Australia. The strategy incorporates five main activities:

- monitoring and case finding;

- case management;

- public education and health promotion;

- remediation of public land;

- evaluation, research and development.

\section{MONITORING AND CASE FINDING}

Monitoring and case finding activities underpin the entire strategy. Between 1991 and 1993, children were recruited to annual surveys conducted usually during the spring months. Since 1994 a voluntary screening service has been offered to families with young children aged between seven months and five years. The service is available on a weekly basis for blood testing, to answer questions, and to provide information and advice about lead-safe practices and behaviours. The number of children aged between one

\section{TABLE 1}

BLOOD LEAD SURVEYS IN BROKEN HILL CHILDREN AGED 1-4 YEARS

\begin{tabular}{|c|c|c|c|}
\hline Year & $\begin{array}{l}\text { Number of } \\
\text { children } \\
\text { surveyed }\end{array}$ & $\begin{array}{l}\text { Estimated } \\
\text { number of } \\
\text { children in } \\
\text { Broken Hill }\end{array}$ & $\begin{array}{l}\text { Estimated } \\
\text { response } \\
\text { rate } \\
\%\end{array}$ \\
\hline 1991 & 781 & 1423 & 55 \\
\hline 1992 & 731 & 1370 & 53 \\
\hline 1993 & 538 & 1316 & 41 \\
\hline 1994 & 948 & 1263 & 75 \\
\hline 1995 & 780 & 1209 & 65 \\
\hline 1996 & 569 & 1156 & 49 \\
\hline 1997 & 733 & 1137 & 65 \\
\hline 1998 & 814 & 1118 & 73 \\
\hline 1999 & 734 & 1099 & 67 \\
\hline 2000 & 633 & 1080 & 59 \\
\hline 2001 & 624 & 1061 & 59 \\
\hline Note: & \multicolumn{3}{|c|}{$\begin{array}{l}\text { Population estimates are calculated onthe basis } \\
\text { of the trend suggested by the 1991, } 1996 \text { and } \\
2001 \text { ABS census (ABS 1991, ABS 1996, ABS } \\
\text { 2001). }\end{array}$} \\
\hline
\end{tabular}

and four years screened annually ranged between 538 and 948; response rates varied between 39 per cent and 73 per cent, with a trend towards an increased response over time (Table 1).

\section{CASE MANAGEMENT}

Young children with blood levels $\geq 15 \mu \mathrm{g} / \mathrm{dL}$ were referred for case management. This involved visits by 'lead' nurses and technical officers to assess the home environment. Environmental sampling determined possible sources of contamination in and around the home, and family members were assessed to gauge compliance with 'lead safe' behaviours, for example house cleaning practices and hand washing. Evidence of pica habits (an abnormal craving to ingest substances such as clay, dirt or hair) was also sought. The home visits were an opportunity to provide advice and support for parents to enable them to take action to reduce the exposure of their children to, and intake of, lead. 
For children who had substantially-elevated blood lead levels, the sources of lead in the home environment were systematically removed. Home remediation included removing ceiling dust, removing or covering contaminated soil around the home, stabilising flaking lead-based paints, cleaning or replacing carpets, cleaning soft furnishings and addressing structural problems in the home that did not adequately prevent dust ingress (that is, in walls, ceilings and floors).

\section{PUBLIC EDUCATION AND HEALTH PROMOTION}

The Broken Hill community was kept informed and involved in the Lead Management Program through regular media coverage and other promotional activities. Programs to modify behaviour included curriculum-based lead education in primary schools, and accredited training for groups such as the local council, the water authority, nurseries, hardware stores and trades. The purpose of these activities was to raise community awareness about lead, to promote and encourage use of the lead management services, and to provide information and advice to parents and children about 'lead safe' behaviours.

\section{REMEDIATION OF PUBLIC LAND}

A community-wide environmental assessment of public land was undertaken, to map lead concentrations and soil stability. Sites were then categorised according to the perceived risk of dispersion of lead to adjacent residential areas. Cost estimates for the remediation of high-risk sites were prepared and remediation works were prioritised. The urgency to act was tempered by an assessment that the benefits derived from this type of land remediation were likely to be less immediate than those that targeted families and their immediate home environment. Further, the projected benefits from the remediation of public land would depend in the first instance on the effective handling of pre-existing contamination in and around homes and the adoption of lead safe behaviours within the community.

\section{EVALUATION, RESEARCH, AND DEVELOPMENT}

A population-based register of preschool children presenting for blood lead screening has existed since 1991 and contains information on birth cohorts from 1987. Data from the register forms part of the evaluation strategy for the Lead Management Program. Research is used to report on the outcomes from the Program, to develop an understanding of the sources and pathways of lead exposure in Broken Hill, to evaluate specific components of the Program, and to respond to emerging issues. For example, home remediation was evaluated to determine its effectiveness in reducing blood lead levels.

Overall blood lead levels in young children have halved since the Program began in 1991. The age-sex standardised mean blood lead level has decreased from $16.7 \mu \mathrm{g} / \mathrm{dL}$ to $7.0 \mu \mathrm{g} / \mathrm{dL}$ between 1991 and 2002 (Figure 1). These reductions have been consistently observed irrespective of the age of the child or the location of the home in the town.

\section{FIGURE 1}

AGE SEX STANDARDISED GEOMETRIC MEAN BLOOD LEAD CONCENTRATION OF CHILDREN SCREENED AGED BETWEEN 1 AND 4 YEARS, BROKEN HILL, NSW, 1991-2002

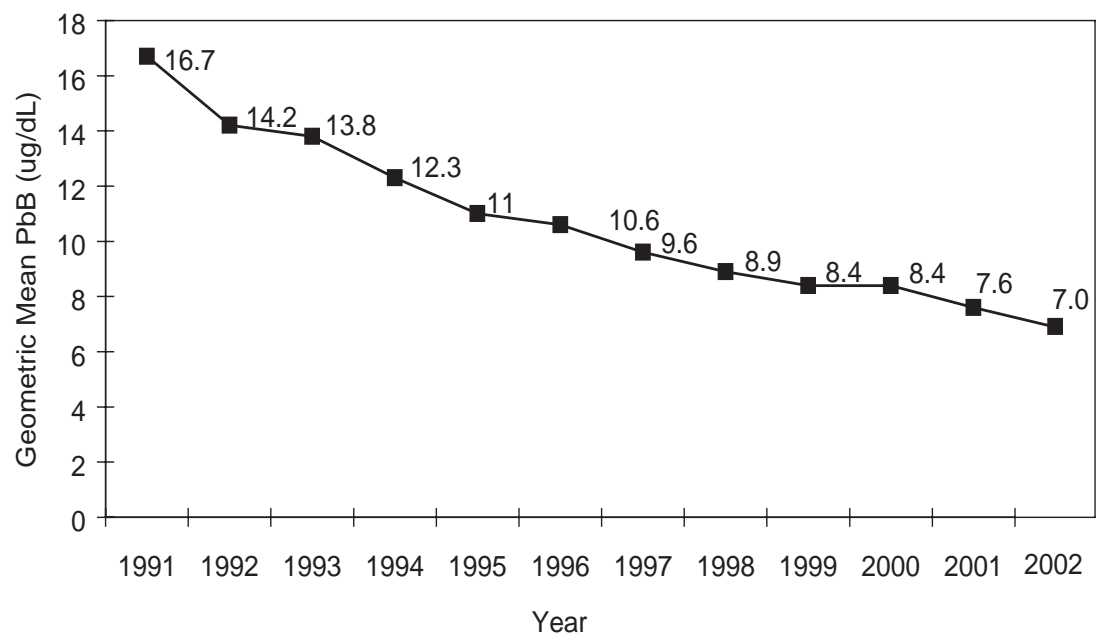

Blood Lead Concentration

Source: Broken Hill Environmental Lead Centre 
TABLE 2

AGE SEX STANDARDISED PERCENTAGE OF BROKEN HILL CHILDREN IN EACH BLOOD LEAD CATEGORY, AGED 1-4 YEARS, 1991-2001

\begin{tabular}{|lrrrrrrrrrrr}
\hline $\begin{array}{l}\text { Blood lead } \\
\text { concentration }\end{array}$ & $\mathbf{1 9 9 1}$ & $\mathbf{1 9 9 2}$ & $\mathbf{1 9 9 3}$ & $\mathbf{1 9 9 4}$ & $\begin{array}{r}\text { Year } \\
\mathbf{1 9 9 5}\end{array}$ & $\mathbf{1 9 9 6}$ & $\mathbf{1 9 9 7}$ & $\mathbf{1 9 9 8}$ & $\mathbf{1 9 9 9}$ & $\mathbf{2 0 0 0}$ & $\mathbf{2 0 0 1}$ \\
\hline$>29 \mu \mathrm{g} / \mathrm{dL}$ & 11.5 & 8.2 & 8.2 & 4.2 & 3.6 & 2.2 & 1.9 & 1.3 & 1.1 & 1.4 & 1.2 \\
$20-29 \mu \mathrm{g} / \mathrm{dL}$ & 28.7 & 17.8 & 20.5 & 13.4 & 12.6 & 10.6 & 8.6 & 5.1 & 6.5 & 5.8 & 4.2 \\
$15-19 \mu \mathrm{g} / \mathrm{dL}$ & 21.6 & 21.4 & 16.7 & 16.8 & 14.7 & 17.5 & 11.8 & 12.0 & 9.1 & 9.0 & 9.8 \\
$10-14 \mu \mathrm{g} / \mathrm{dL}$ & 24.6 & 32.3 & 28.4 & 33.0 & 27.5 & 26.2 & 28.8 & 28.8 & 25.8 & 25.4 & 20.6 \\
$<10 \mu \mathrm{g} / \mathrm{dL}$ & 13.6 & 20.4 & 26.2 & 32.6 & 41.7 & 43.5 & 48.9 & 52.9 & 57.5 & 58.3 & 64.2 \\
\hline
\end{tabular}

Source: Broken Hill Environmental Lead Centre

By 2001, the majority (64 per cent) of preschool-aged children were below the NHMRC goal for all Australians $(10 \mu \mathrm{g} / \mathrm{dL})$ up from only $13.6 \%$ in 1991 . There was also a reduced proportion of children with significantly elevated blood levels (> $15 \mu \mathrm{g} / \mathrm{dL}$ ), down from 61.2 per cent in 1991 to 15.2 per cent in 2001 (Table 2).

Following the success of the initial focus on children with established lead problems, the Program is now moving to establish early intervention strategies. There is now a reduced need for, and emphasis on, home remediation and consequently the Program is able to increase its investment in community-wide work. For example, in 1996 the monitoring program was extended to include the measurement of lead levels in pregnant women and neonates (via cord blood), to identify families where early intervention was indicated before or around the time of birth of the child. It was argued that modifying environmental hazards in and around the home and adopting more appropriate lead-safe behaviours from birth may reduce a baby's overall lead exposure and obviate the need for later home remediation.

\section{CONCLUSION}

Substantial progress has been made in dealing with the exposure to lead of Broken Hill children. Nonetheless work is still needed to reduce the proportion of these children with significantly elevated blood lead levels (> $15 \mu \mathrm{g} / \mathrm{dL}$ ) from the 2001 figure of 15.2 per cent to the NHMRC target of five per cent.

\section{ACKNOWLEDGEMENTS}

We wish to acknowledge the efforts of Dr John Hall, Andrew Phillips, John O'Gorman, Dr Stephen Corbett, Dr Mark Jacobs, Sean Reddan, Daniel Stokes, Francis Boreland, Stephen Begg, Marcia Lively, Vilmae McManus, Angela Tiziani, Sheryl Chapman, other past and present staff of the Broken Hill Environmental Lead Centre, and the local paediatricians who supported the program and the Community Working Party.
An overview of the Broken Hill Environmental Lead Program was published in a previous issue of the NSW Public Health Bulletin (Volume 12, Number 6). ${ }^{5}$ This article is adapted from the previous article, with the inclusion of results of blood lead level test for children less than five years of age and expectant mothers from 1991 to 2001.

For further information on environmental lead, and lead and health, go to the Leadsafe site on the NSW Environment Protection Authority web page: www.epa.nsw.gov.aulleadsafe/index.

The links section provides a useful resource on agencies and organisations involved in lead issues.

For additional information on the Broken Hill Lead Management Program, contact:

- Lead Program Team Leader, Broken Hill Child and Family Centre (08) 8082 6111; or

- Far West Population Health Unit (08) 80801499.

\section{REFERENCES}

1. Solomon U. The Richest Lode, Broken Hill 1883-1988. Sydney: Hale and Iremonger, 1988.

2. Ashburton Thompson J. Report of Board appointed to inquire into the prevalence and prevention of lead poisoning at the Broken Hill silver-lead mines. Sydney: NSW Legislative Assembly Government Printer, 1898.

3. National Health and Medical Research Council. Lead in Australians. Statement issued by the 115 th session of NHMRC. Revision 1987 (103rd session) guidelines. Sydney: NHMRC, 1993.

4. Woodward-Clyde Pty Ltd. Evaluation of Environmental Lead at Broken Hill. Sydney: Environmental Protection Authority, 1993.

5. Lyle D, Balding B, Burke H, Reddan S. NSW Lead Management Program in Broken Hill. N S W Public Health Bull 2001;12(6):165-7. H 